\title{
VARIACIONES INTERANUALES DEL BALANCE HIDRICO EN TERUEL
}

\author{
Miguel SANCHEZ FABRE \\ Universidad de Zaragoza
}

\begin{abstract}
Resumen: A partir de los datos medios de temperaturas y precipitaciones del periodo 1948/49 - 1988/89, se elabora una ficha de balance hidrico medio. Posteriormente, seleccionando 11 años de características pluviométricas bien diferenciadas se construyen las correspondientes fichas hídricas; éstas se analizan comparando sus datos con los constatados en la primera.
\end{abstract}

Abstract: From mean temperatures and rainfall data for the period 1948/49 - 1988/89, an medium hydric balance index card is elaborated. Then, selecting 11 years with differential pluviometric characteristics, the corresponding hydric index cards are made; these are analysed comparing its data with the ones verified in the original.

Palabras Clave: Balance hídrico, variaciones interanuales, Teruel.

Sumario: Introducción.- Consideraciones metodológicas.- Análisis de la ficha de balance hídrico del periodo 1948/49 - 1988/89.- Análisis de las diferentes fichas de balance hídrico.- Conclusión.- Bibliografía.

\section{INTRODUCCION}

La ciudad de Teruel se ubica en el interior de una de las depresiones intramontañosas de la Cordillera Ibérica. Su localización es factor determinante del dominio de un clima continental bastante matizado por las influencias mediterráneas. Desde el punto de vista de la aridez y la evapotranspiración, que son los elementos que en este trabajo nos interesan especialmente, los diferentes trabajos existentes son unánimes en señalar que el clima de Teruel es semiárido (ASCASO y CUADRAT, 1981; SANCHEZ-FABRE, 1984 y 1989; PEÑA et al., en prensa).

Partiendo de esta definición como clima semiárido, y sin perder en ningún momento su perspectiva, el objetivo de este estudio es analizar si el grado de aridez de la zona sufre 
variaciones significativas en función del total de precipitaciones recogido anualmente y de su distribución estacional. El parámetro a través del cual hemos intentado detectar estas alteraciones es el balance hídrico, calculado a partir del método de Thornthwaite y expresado en las correspondientes fichas hídricas. En nuestras conclusiones intentaremos resaltar aquellas variaciones, si las hay, que destaquen en los casos estudiados y que, al mismo tiempo, consideremos que podrían caracterizar el clima de la zona.

En definitiva, lo que pretendemos con nuestro trabajo es realizar una primera aproximación al conocimiento del balance hídrico, por la importancia que tiene para saber las disponibilidades hidrológicas de una cuenca, normalmente deficitaria, y consiguientemente de sus embalses, que deben utilizarse para abastecimiento de aguas potables, riegos, uso industial, etc. Definir las características del balance hidrográfico en una zona más amplia que la estudiada (cuenca hidrográfica) puede permitir la previsión de necesidades de agua y una adecuada utilización de la misma. Por otra parte, poner en relación las eventualidades del balance hídrico con la producción de los correspondientes años agrícolas permite valorar la incidencia que tiene la variación de la reserva de agua en el rendimiento de determinados cultivos de secano afectados por estas circunstancias. Finalmente, desde una perspectiva geomorfológica el balance hídrico tiene reflejo en el poder de erosión del suelo alcanzado por las lluvias torrenciales que se producen en la zona de estudio en determinadas épocas del año. La existencia durante dichas épocas de una reserva de agua en el suelo, favorece el desarrollo de un recubrimiento vegetal, constituído por formaciones estépicas muy sensibles al comportamiento hidrológico, que amortigua el poder erosivo de las precipitaciones.

\section{CONSIDERACIONES METODOLOGICAS}

El primer paso en nuestro trabajo ha consistido en la recogida de los datos climáticos necesarios para elaborar las corespondientes fichas hídricas. Hemos completado una serie de 41 años (1948-49 - 1988-89) perteneciente a la estación situada en Viveros de Obras Públicas. En este caso hemos preferido utilizar estos datos, y no los del propio observatorio del Instituto Nacional de Meteorología, debido a que aportan una serie más continua y sobre todo mucho más extensa en el tiempo. Con los datos medios mensuales de temperaturas y precipitaciones, correspondientes al conjunto de los 41 años hemos configurado una primera ficha hídrica que confirma el citado carácter semiárido del clima 
turolense. Luego, hemos seleccionado varios años de características pluviométricas bien diferenciadas para ver como evoluciona el balance hídrico en cada caso, y establecer una comparación con la ficha hídrica que define la situación media para el periodo de tiempo estudiado.

Respecto al tratamiento de los datos debemos aclarar dos cuestiones:

- Al elaborar las fichas hídricas anuales nos ha parecido logico utilizar en ellas datos correspondientes a años hidrológicos. Emplear la división en años convencionales no tiene sentido, ya que el iniciarse la ficha hídrica en Septiembre u Octubre las lluvias caídas en estos últimos meses del año tendrán su influencia en lo que ocurra al año siguiente, pero en ningún caso en lo acontecido con anterioridad en ese mismo año. Además, la utilización del año hidrológico nos permite delimitar perfectamente el inicio de cada época de lluvias, arrancando de él, y hacer el seguimiento de las mismas y de su influjo hasta llegar al periodo seco que de manera generalizada y casi indefectible establece el agotamiento de las reservas de agua, y, por tanto un nuevo punto de arranque cuando acabe y vuelvan las precipitaciones en otoño.

- A la hora de hallar el reparto estacional de las precipitaciones, hemos agrupado los datos mensuales del siguiente modo:

- Otoño: Octubre, Noviembre y Diciembre.

- Invierno: Enero, Febrero y Marzo.

- Primavera: Abril, Mayo y Junio.

- Verano: Julio, Agosto y Septiembre.

Esto facilita la adaptación de los datos obtenidos al año hidrológico, así como la elaboración de las fichas hídricas arrancando de Octubre. Además, hay que tener presente que con esta división, que quizás no es la más tradicional, agrupamos en cada estación los meses con mayor número de días pertenecientes a ella. Por otra parte, no debemos olvidar las características climáticas propias de la zona, con una sequía estival que se alarga durante la mayor parte de Septiembre, y una primavera y verano térmicos muy tardíos. 


\section{ANALISIS DE LA FICHA DE BALANCE HIDRICO DEL PERIODO $1948 / 49-1988 / 89$}

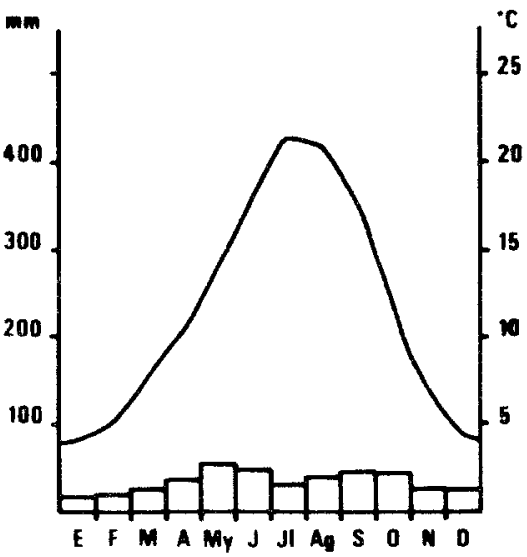

Fig. 1. Diagrama de temperaturas y precipitaciones. Observatorio de Viveros de Obras Públicas (Teruel). Periodo 1948/49 - 1988/89.
Como ya hemos indicado nos interesa inicialmente conocer los datos medios relativos al conjunto de 41 años considerados, para poder, posteriormente, apreciar hasta que punto se ajustan o se alejan de ellos las cifras anuales. Con esta finalidad hemos elaborado el gráfico de la figura 1, a partir de los valores medios mensuales de temperatura y de precipitaciones del periodo observado (1948/49 - 1988/89). En él se evidencian las bajas temperaturas invernales (Enero $4^{\circ}$ ), la relativa suavidad de las temperaturas veraniegas (Julio 21'3o, Agosto 20'90) y la gran oscilación térmica anual (17'30); en relación con las precipitaciones, destacan su relativa escasez $\left(410^{\prime} 2 \mathrm{~mm}\right.$.), el máximo

primaveral (34\% del total) y el máximo secundario de finales de verano comienzos de otoño, y el mínimo invernal, ya que en esta época tan sólo se recoge el $15 \%$ del total de las precipitaciones anuales.

Los mismos datos con los que se ha diseñado la figura 1 sirven como punto de partida para la realización de la ficha hídrica (Cuadro 1). En ella, llama poderosamente la atención el hecho de que la evaporación potencial $\left(683^{\prime} 4 \mathrm{~mm}\right.$.) total anual, supera ampliamente el total de precipitaciones (410'2 mm.); a su vez, la evaporación real es la misma que dicho total de precipitaciones, lo cual supone, al menos teóricamente, que toda el agua precipitada se evapora.

Interesa, también, ir viendo la evolución del balance hídrico a lo largo del año. Inicialmente, en Octubre, la evaporación potencial es superior a las precipitaciones, por lo que el agua caída en éstas se evapora, y el balance es deficitario. A partir de Noviembre y 

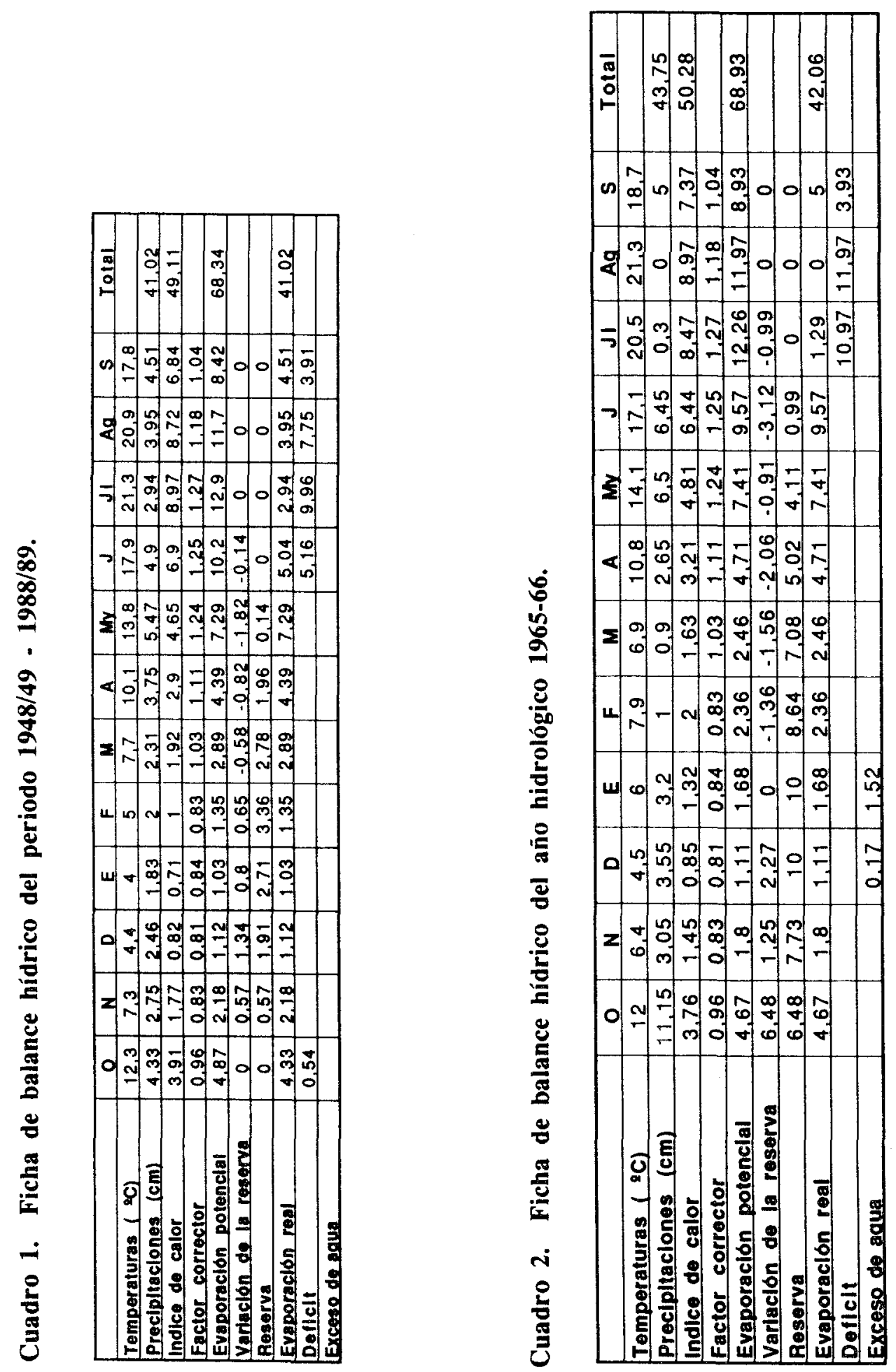
hasta Febrero las precipitaciones superan a la evaporación potencial, por lo que se va acumulando una reserva de agua en el suelo que alcanza un máximo de 3'36 cm. Desde Marzo nuevamente el agua potencialmente evaporada es mayor que la aportada por las precipitaciones. Esto hace que se vaya consumiendo el agua de la reserva, que se agota definitivamente en Junio. Durante este mes ni siquiera la suma del agua de las lluvias y la escasa reserva existente, es suficiente para que la evaporación real sea equivalente a la potencial, como venía sucediendo desde Noviembre, por lo que de nuevo se hace patente el déficit de agua. En los meses de verano las precipitaciones son muy inferiores a la evaporación potencial, alta en función de las elevadas temperaturas; esto hace que el déficit hídrico sea muy fuerte (Cuadro 1 y Fig. 2).

Aplicando a los valores calculados en esta ficha hídrica, los índices establecidos por Thornthwaite, el clima de Teruel queda clasificado del siguiente modo:

- en función de la eficacia térmica, como MESOTERMICO I ( $\left.\mathbf{B}^{\prime}{ }_{1}\right)$.

- en función de la humedad como SEMIARIDO (D).

- en función de la variación estacional de humedad, como un clima donde el exceso de agua es pequeño o nulo (d).

- también cabe señalar que en los meses de verano se concentra el 48'31\% de la evaporación potencial ( $\left.\mathbf{b}_{4}^{\prime}\right)$.

\section{ANALISIS DE LAS DIFERENTES FICHAS DE BALANCE HIDRICO}

Una vez conocidos los rasgos esenciales de la ficha hídrica que podríamos considerar "tipo" para Teruel, hemos seleccionado 11 años de características pluviométricas bien diferenciadas, para analizar si el balance hídrico que hubo a lo largo de ellos se ajusta o no al establecido con los valores medios de los 41 años observados. En este apartado del trabajo presentamos las fichas de los 11 años y hacemos un breve comentario de cada caso, reseñando aquellos elementos, si los hubiera, que lo hacen peculiar. Tanto el hecho de que algunas de las situaciones son las extremas, como el que no se hayan estudiado varios ejemplos de cada una de ellas, hace que las consideraciones 
que puedan extraerse no deban de valorarse como representativas de cara a fijar tipos de años o de balances hídricos anuales. No obstante, no olvidemos que no es esto lo pretendido. Nuestro sencillo objetivo es apreciar si existen variaciones interanuales importantes en el balance hídrico de Teruel, y ello sí podemos verlo a partir del estudio de los 11 casos señalados.

Hemos elegido el año 1965-66 por la elevada cantidad de precipitaciones caídas en otoño (177'5 mm.). La cifra anual de precipitación (437'5 mm.) es bastante similar a la media $410^{\prime} 2 \mathrm{~mm}$. Ahora bien, si lo normal es que las lluvias caídas en otoño sean algo menos de la cuarta parte de las registradas a lo largo del año, en el caso que analizamos llegan a concentrarse en esta estación el $40 \%$ del total anual. Dentro de los 41 años considerados, hay seis casos en los que las precipitaciones de otoño superan el $30 \%$ del total; de algún modo, el año $1965-56$ podría ser indicativo de lo que ocurriría en ellos.

En este año las precipitaciones comienzan siendo superiores a la evaporación desde Octubre. Por ello, desde este mes hasta Enero se acumula agua en el suelo, llegando a registrarse un exceso de agua en los meses de Diciembre y Enero. A partir de Febrero y ya hasta Septiembre la evaporación potencial supera a las precipitaciones, por lo que se va gastando la reserva, que se agota completamente en Julio, siendo los tres meses de verano deficitarios de agua.

De lo anterior se deduce que las peculiaridades que puede introducir un otoño húmedo en el balance hídrico son esencialmente: una acumulación de reserva desde Octubre, que en el caso analizado establece un momentáneo exceso de agua (Diciembre, Enero); una prolongación del periodo en que hay agua de reserva en el suelo, de modo que el déficit hídrico no comienza en Junio sino que lo hace en Julio (Fig. 2).

Este año se caracteriza pluviométricamente por un total de precipitaciones (472'5 $\mathrm{mm}$.) algo superior a lo habitual (410'2 mm.) y un reparto estacional en el que tanto en otoño como en invierno el porcentaje de precipitaciones medidas (29'2\% y 20\%) es superior al que suelen corresponder a estos periodos ( $233^{\prime} 2 \%$ y $144^{\prime} 9 \%$, respectivamente). Así pues, a la existencia de un otoño relativamente húmedo, rasgo común con la situación previamente descrita, se suma la presencia de un invierno en que las precipitaciones también son importantes, alargándose la época de humedad. Similares circunstancias se repiten en los años 1964-65, 1966-67, 1967-68, 1969-70 y 1986-87. 
Variaciones interanuales del balance hidrico en Teruel
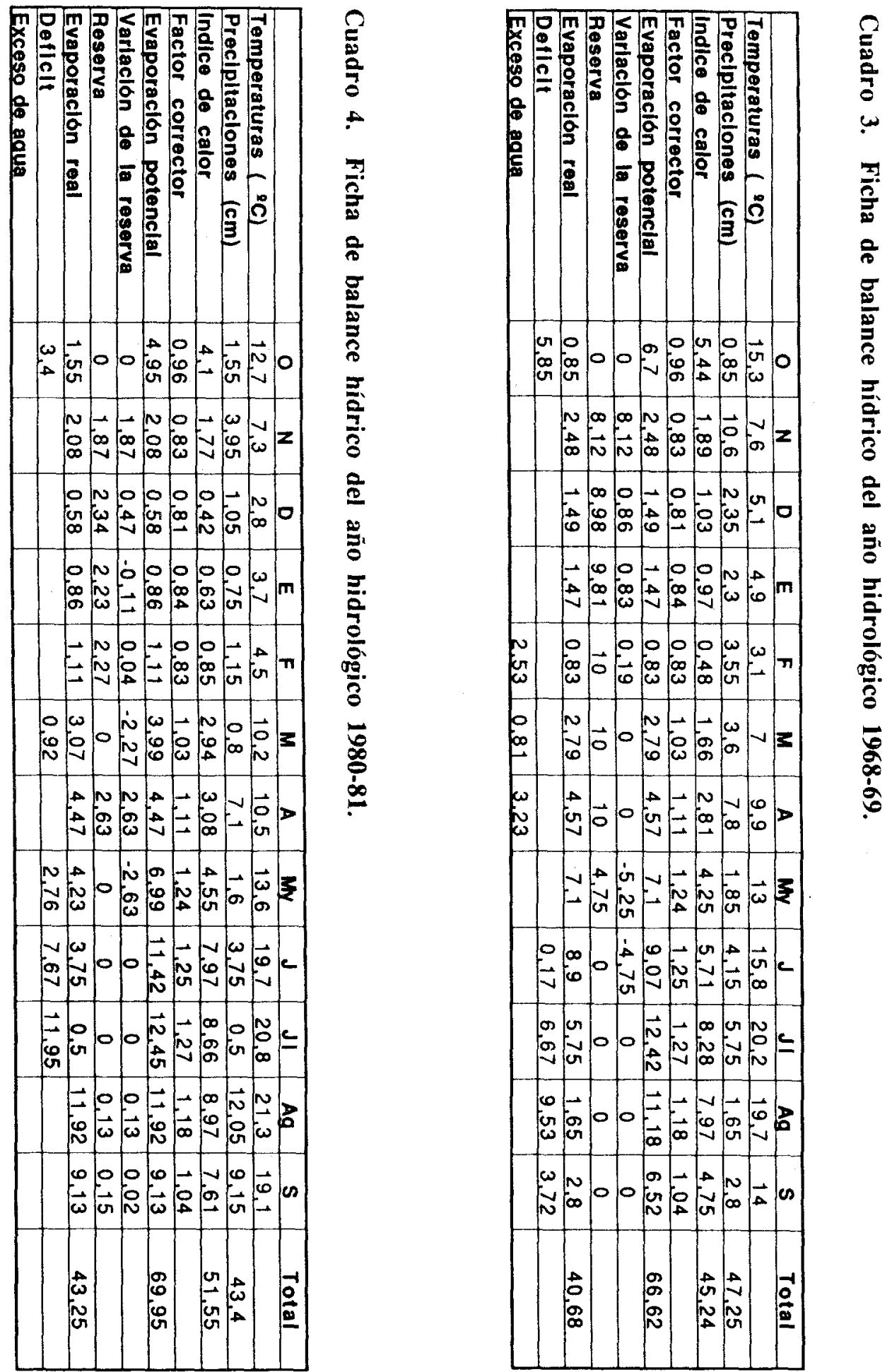
Como habitualmente, es en Noviembre cuando las lluvias superan, por vez primera, las posibilidades de la evaporación, de manera que comienza a acumularse agua de reserva alcanzándose en Febrero un exceso de agua que se prolonga hasta Abril. En Mayo, a medida que descienden las precipitaciones y se elevan las temperaturas, se invierte el sentido del balance. La reserva se agota en tan sólo 2 meses (Mayo y Junio) y, de nuevo, falta agua durante todo el verano.

El rasgo más característico de esta situación es el signo positivo del balance precipitación-evaporación durante la mayor parte del otoño, el invierno, e incluso el inicio de la primavera, en relación directa con la importante cuantía de las precipitaciones. Esto hace que llegue a "sobrar agua" en Febrero, Marzo y Abril. No obstante, esta cantidad significativa de agua acumulada en el suelo $(10 \mathrm{~cm}$.), no llega a permitir que la humedad se extienda más allá de Abril-Mayo, como cabría esperar (Fig. 2).

La elección de este año la hemos realizado fijándonos en la baja cuantía de las precipitaciones tanto en otoño (65'5 mm., $15 \%$ del total anual) como en invierno (27 mm., 62\% del total anual). En conjunto, durante el periodo que va desde Octubre de 1980 a Septiembre de 1981 se midió una cantidad de precipitaciones que podemos calificar como normal (434 mm.). En otros nueve años de la serie estudiada los porcentajes de precipitaciones recogidos durante estas dos estaciones quedan por debajo de los porcentajes medios.

Durante los tres primeros meses de esta época lo acontecido es similar a lo descrito para el conjunto del periodo 1948/49 - 1988/89. Eso sí, al ser bajas las precipitaciones el agua acumulada en la reserva es poca, y como quiera que las lluvias siguen escaseando en invierno, se va a constatar un primer déficit hídrico en Marzo Precisamente, lo temprano del inicio tanto de la variación negativa de la reserva (Enero) como de la llegada del deficit de agua (Marzo), junto a los altibajos que el balance experimenta desde Enero hasta Mayo, son los rasgos distintivos de este año hidrológico. A partir de Mayo la reserva se agota y el déficit de agua se hace palpable hasta Julio. En Agosto y Septiembre las precipitaciones (212 mm., 43\% del total anual) superan muy ligeramente a la fuerte evaporación; no obstante, no es este hecho, muy poco marcado, lo que intentamos evidenciar en este punto (Fig. 2). 

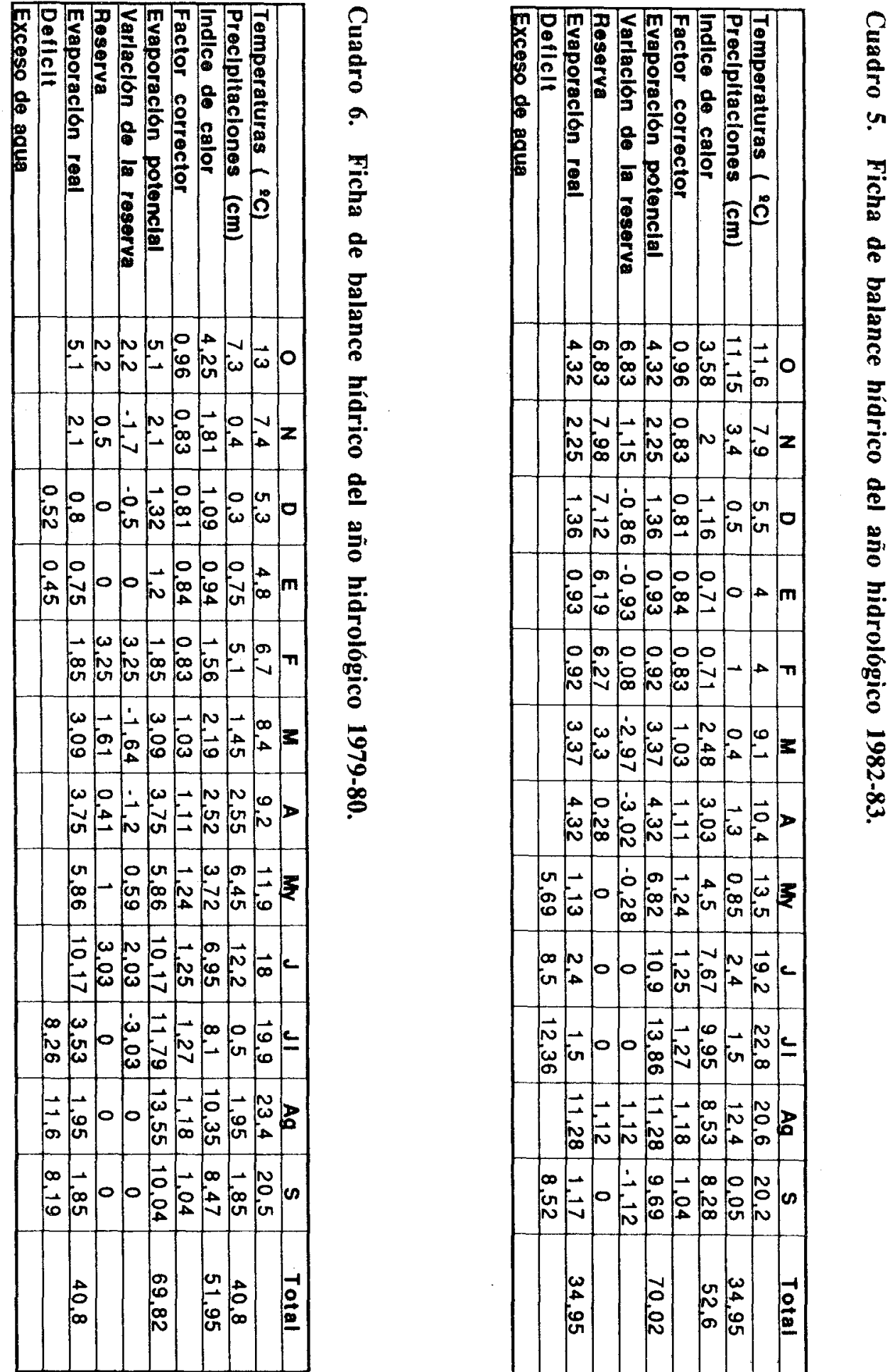
Se trata de un ejemplo de año poco lluvioso (349'5 mm.) en el que aparece muy marcada una primavera seca. En este equinoccio sólamente se contabilizan 45 ' $5 \mathrm{~mm}$. de precipitación frente a los $139^{\prime} 4 \mathrm{~mm}$. que, como dato medio de los 41 años estudiados, caen teóricamente cada primavera. Porcentualmente esto supone que en 1982-83 se concentran en esta época primaveral el $13 \%$ de las precipitaciones, muy lejos del $33{ }^{\circ} 9 \%$ que por término medio le corresponden. Son dieciocho las ocasiones en que las lluvias registradas en primavera quedan por debajo del citado valor porcentual medio; de ellas, solamente tres no llegan a suponer el $20 \%$ del total anual, siendo este total durante 1985 86 muy similar al del año que analizamos.

En Octubre y Noviembre sólo una parte del agua precipitada se evapora, por lo que queda una reserva en el suelo. Desde Diciembre hasta Mayo, con la excepción casi inapreciable de Febrero, las precipitaciones son escasas y no llegan a cubrir las posibilidades de evaporación, dado lo cual la reserva se agota paulatinamente y ya en Mayo se registra un déficit de agua. Esta situación deficitaria del balance hídrico, sólamente se interrumpe en Agosto, al registrarse $124 \mathrm{~mm}$. de lluvia que suponen más de un tercio del total anual.

El dato que nos parece más interesante en esta ficha es que, en función de la escasez de precipitaciones caídas en primavera, el agotamiento de la reserva y el comienzo del periodo deficitario en agua se adelanta, respecto a la situación media, desde Junio hasta Mayo (Fig. 2).

Al contrario que en el caso anterior, en 1979-80 de los $408 \mathrm{~mm}$. medidos en el observatorio de Obras Públicas de Teruel, $212 \mathrm{~mm}$. (51'9\% del total) se inscriben en el equinoccio de primavera. Podemos pues hablar de una primavera húmeda, ya que se superan con creces los datos medios establecidos para esta zona (139'4mm.; 33'98\% del total anual). Dentro de la serie estudiada, se constatan ocho años en los que más del $45 \%$ de las precipitaciones se concentran en primavera, incluso en cuatro de ellos más del $50 \%$. Los ocho años tienen unos totales anuales de precipitaciones muy variables, siendo muy similar al del ejemplo considerado el del año 1963-64.

Durante el año hidrológico 1979-80, el balance precipitaciones-evaporación resulta muy irregular desde Octubre hasta Abril. En Octubre se genera una reserva de agua que se agota en los dos meses siguientes, llegando a ser deficitarios en agua Diciembre y Enero. 
En Febrero vuelve a acumularse algo de agua en el suelo, que se consume, en su mayor parte, durante Marzo y Abril para cubrir la diferencia existente entre las lluvias de estos dos meses y la evaporación potencial. En Mayo y Junio, gracias a las abundantes precipitaciones el suelo vuelve a recuperar humedad y almacena agua. Esta desaparece en Julio, debido a la fuerte evaporación, y en verano se manifiesta el típico deficit hídrico.

Sin duda el elemento original de esta situación viene marcado por las elevadas precipitaciones de primavera, y se concreta en un retraso del inicio del periodo deficitario de agua hasta Julio (Fig. 2).

Aunque el año 1954-55 destaca también por la escasez de precipitaciones recogidas en otoño, nosotros lo hemos elegido debido a la elevada cuantía de las registradas durante el verano. Así, de los $497^{\prime} 4 \mathrm{~mm}$. medidos durante este periodo anual, 221'3 mm. (44'4\%) se concentraron en la estación estival. Resulta bastante frecuente que las precipitaciones recogidas durante el verano sean cuantiosas, de manera que encontramos nueve años en que suponen más del 35\% del total anual, estando en cinco casos por encima del $40 \%$ y superando en dos el $50 \%$. En ocho de estos nueve años, las lluvias medidas en verano están en torno a $200 \mathrm{~mm}$., que se sobrepasan en cuatro ocasiones.

La ficha hídrica se inicia reflejando las escasas lluvias otoñales, a través de la existencia de un déficit no muy acusado. En invierno asistimos a un aumento de la precipitación, que trae consigo la acumulación de ciertas reservas de agua en el suelo. Estas pocas reservas se agotan rápidamente al ascender las temperaturas en primavera y con ellas la evaporación potencial. De esta forma, en Abril desaparece completamente la reserva y desde este mes hasta Septiembre el balance hídrico queda definido por el déficit de agua.

Nos interesa destacar de esta ficha hídrica que, a pesar de las abundantes lluvias estivales, en todo el periodo de verano hay un déficit hídrico, si bien resulta menos acentuado cuantitativamente que en otros años. Por otro lado, la concentración de gran parte de las lluvias anuales en el solsticio de verano, hace que encontremos un otoño seco, de modo que, aunque las precipitaciones de invierno y primavera alcanzan valores normales, el periodo de concentración de agua en el suelo queda muy reducido. Como consecuencia hay un primer déficit de agua en el propio otoño y el inicio del déficit característico de finales de primavera y verano se adelanta nada menos que hasta Abril (Fig. 2). 

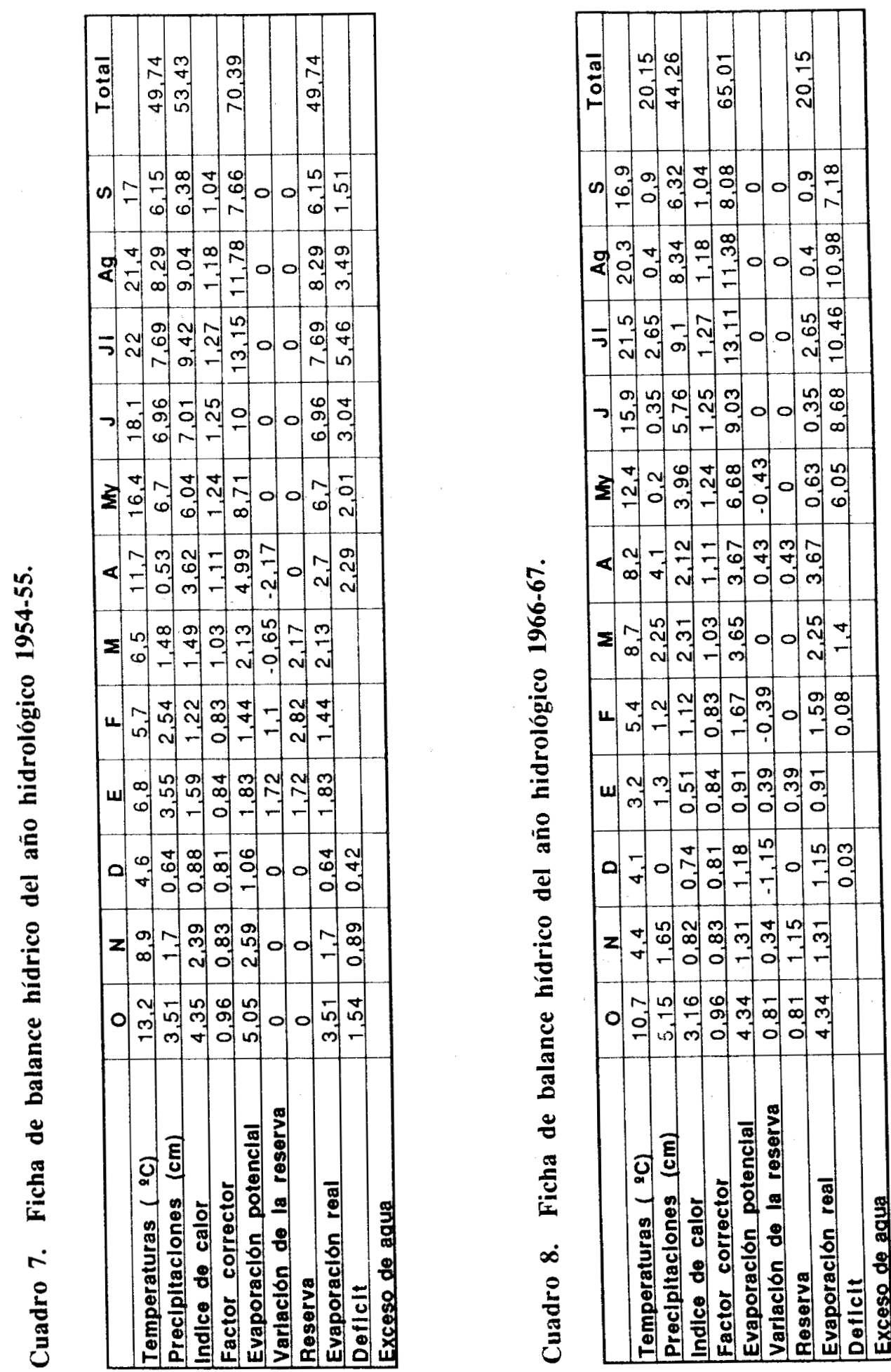
Su elección se debe a la reducida cantidad de precipitaciones registradas en este periodo (201'5 mm.). Tanto en Octubre y Noviembre como en Enero y Abril se crea una reserva de agua en el suelo. Sin embargo, dada la escasa cuantía general de las precipitaciones, el agua de reserva desaparece en los meses que se intercalan entre los citados, pasándose en ellos a una situación deficitaria de agua. En Mayo la reserva se acaba definitivamente, iniciándose un periodo seco en el que las cantidades que evalúan el déficit llegan a ser muy elevadas.

Los datos que diferencian esta ficha son: la prolongación del periodo seco, muy acentuado, desde Mayo hasta Septiembre, y las fluctuaciones de signo, positivo o negativo que experimenta el balance hídrico en el resto del año.

También este año hidrológico lo hemos escogido por su sequedad (267'5 mm.). Su otoño responde a la situación normal: un mes de Octubre en que no llega a llover tanta agua como podría evaporarse y, a continuación, el comienzo de concentración de agua en el suelo. Desde Febrero, ya como consecuencia de la escasez de precipitaciones, la variación de la reserva se vuelve negativa, acabándose en Abril. Desde este mes se observa un déficit de agua que se prolonga durante toda la primavera y el verano.

El rasgo más característico de esta ficha, común al de la anterior, es la larga duración del periodo seco (Abril-Septiembre), y la enorme cantidad de agua que llega a faltar en Junio, Julio y Agosto (Fig. 2).

Debemos significar que en la serie climática considerada existen siete años en que las precipitaciones totales no alcanzan los $300 \mathrm{~mm}$.

La elevada cifra de precipitaciones $(616 \mathrm{~mm}$.) contabilizada durante este periodo es el motivo de que lo hayamos seleccionado para elaborar su ficha de balance hídrico. En la misma se observa, desde el propio mes de Octubre, como la cuantía de las lluvias permite que se concentre agua en el suelo, de forma que el mes siguiente éste posee toda el agua que es capaz de retener, $\mathrm{e}$ incluso se produce un exceso de agua. 


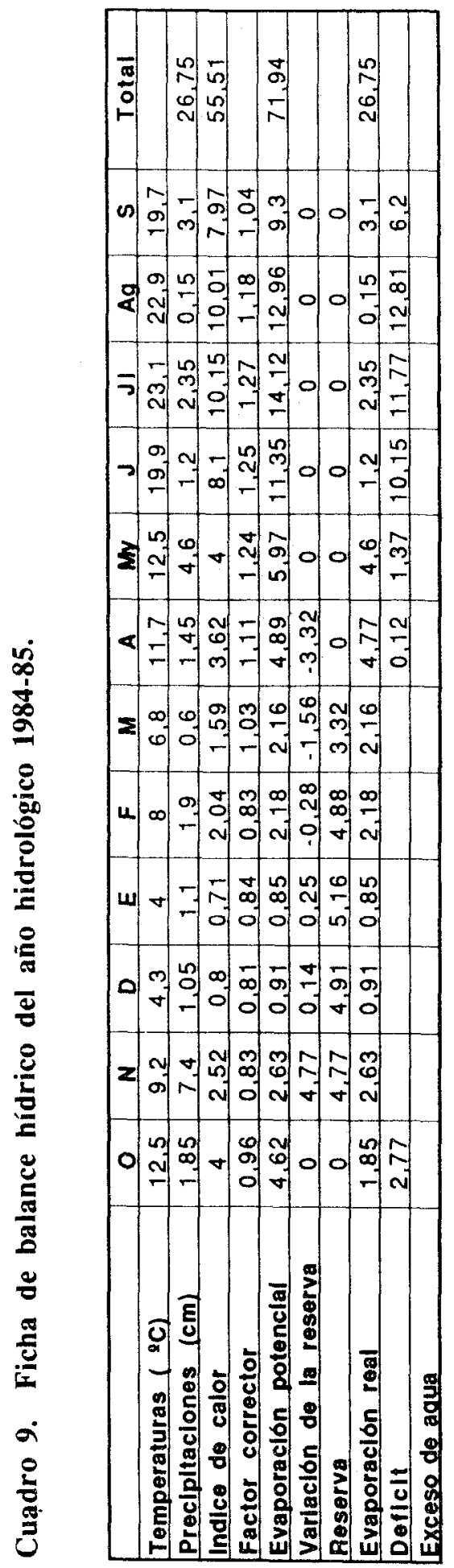

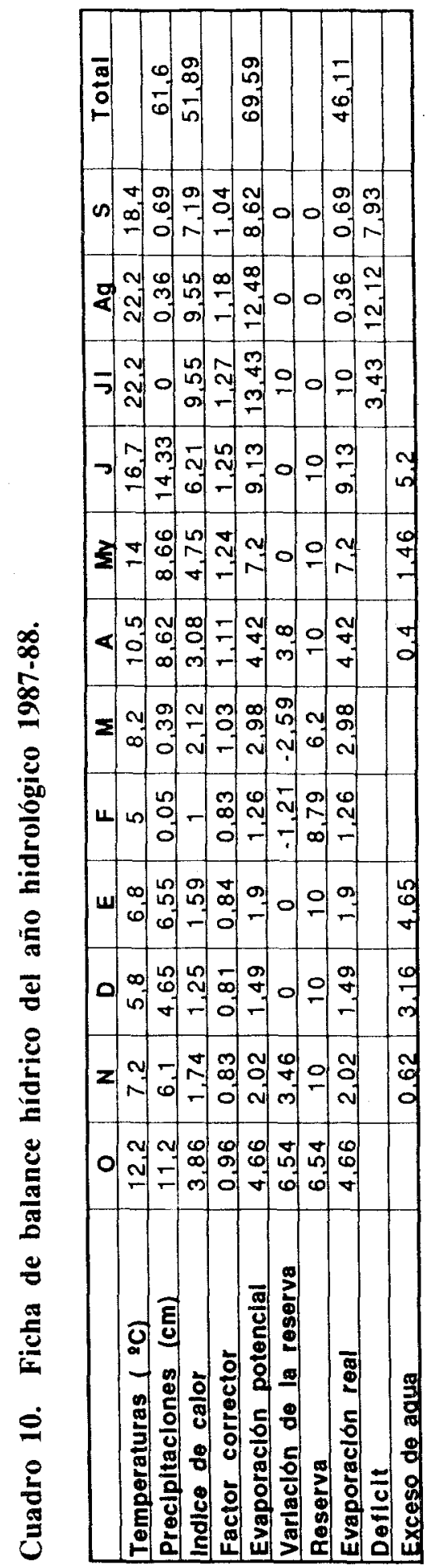


En los meses de Febrero y Marzo las lluvias son escasas y en consecuencia no cubren las posibilidades de evaporación; esto hace que haya una variación negativa de la reserva y que desaparezca el exceso de agua. No obstante, la reserva de agua sigue siendo importante y al incrementarse de nuevo las precipitaciones en Abril, el suelo vuelve a saturarse de agua, y hay un excedente de ella durante los tres meses de primavera. El valor que las temperaturas alcanzan en Julio conlleva una evaporación potencial tan fuerte, que, rápidamente, se agota la reserva del suelo e incluso se establece un déficit hídrico que subsiste todo el verano.

Sin duda, lo más representativo de esta situción es la pervivencia de una reserva considerable de agua en el suelo desde Octubre hasta Junio, apreciándose durante seis meses de esta etapa un exceso de agua. Junto a esto el hecho de que el periodo de sequía comienza tarde, en Julio, pero ni las elevadas precipitaciones ni la gran reserva de agua impiden su existencia.

Durante este periodo el total de precipitaciones alcanza los $637^{\circ} 9 \mathrm{~mm}$., quedando $227 \mathrm{~mm}$. por encima del valor medio (410'2 mm.). Estos dos datos han hecho recomendable su elección, teniendo además en cuenta que son nueve los años del periodo estudiado en los que la precipitación anual supera los $500 \mathrm{~mm}$., e incluso rebasa en tres de ellos los $600 \mathrm{~mm}$.

El año empieza con el déficit hídrico característico de Octubre. Más tarde, desde Noviembre hasta Mayo alternan meses con balance hídrico positivo (Noviembre, Diciembre, Febrero, Marzo y Mayo) y negativo, conservándose de manera continuada una reserva de agua apreciable en el suelo, pero sin llegarse nunca a la saturación. En Junio, la variación de la reserva adquiere un sentido negativo muy acentuado, de modo que al mes siguiente no queda agua en el suelo. Se inicia entonces una etapa de sequía que dura exclusivamente Julio y Agosto, ya que en Septiembre se registra tal número de precipitaciones que el suelo llega a saturarse de agua, quedando incluso una pequeña cantidad "sobrante".

Dos rasgos diferenciales de esta situación son comunes con los de la anterior:

- una larga fase con agua de reserva en el suelo, que en este caso se extiende desde Noviembre hasta Junio. 
Cuadro 11. Ficha de balance hídrico del año hidrológico 1958-59.

\begin{tabular}{|c|c|c|c|c|c|c|c|c|c|c|c|c|c|}
\hline & 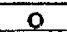 & $\bar{N}$ & $\mathrm{p}$ & $E$ & $F$ & $M$ & A & Mv. & $\downarrow$ & d1 & $A Q$ & $\mathbf{s}$ & Total \\
\hline Temperaturas $\left({ }^{\circ} \mathrm{C}\right)$ & 10.4 & 5 & 4 & 1.9 & 4.3 & 7.4 & 11,6 & 16.2 & 18.5 & 21.3 & 21 & 17.8 & \\
\hline Preclpitaciones $(\mathrm{cm})$ & 3.53 & 3.54 & 2.32 & 4.45 & 5.21 & 4.12 & 8.9 & 4.22 & 15.38 & 5.12 & 0.3 & 2.48 & 59.57 \\
\hline Indice de calor & 3.03 & 1 & 0.71 & 0.23 & 0.8 & 1.81 & 3.58 & 5.93 & 7.85 & 8.97 & 8.78 & 6.9 & 49.59 \\
\hline Factor corrector & 0.96 & 0.83 & 0.81 & 0.84 & 0.83 & 1.03 & 1.11 & 1.24 & 1.25 & 1.27 & 1.18 & 1.04 & \\
\hline Evaporación potenclal & 3.92 & 1,33 & 0.98 & 0.39 & 1.1 & 2.73 & 5.21 & 2.21 & 11.37 & 12.92 & 11,8 & 8.48 & 69.14 \\
\hline Varlaclón de la reserva & $-0,39$ & 0.39 & 0 & 0 & 0 & 0 . & 0 & -4.69 & 4.01 & -7.8 & -1.52 & 0 & \\
\hline Reserva & 9.61 & 10 & 10 & 10 & 10 & 10 & 10 & 5.31 & 9.32 & 1.52 & $e$ & 0 & \\
\hline Evaporaclón real & 3.92 & 1.33 & 0.98 & 0.39 & 1,1 & 2.73 & 5.21 & 8.21 & 11.37 & 12.92 & 1.82 & 2.48 & 53.16 \\
\hline Deflcit & & & & & & & & & & & 2.89 & 6 & \\
\hline Excese de equs & & 182 & 1.34 & 4.06 & 4.11 & 139 & 3.69 & & & & & & \\
\hline
\end{tabular}

Cuadro 12. Ficha de balance hídrico del año hidrológico 1959-60.

\begin{tabular}{|c|c|c|c|c|c|c|c|c|c|c|c|c|c|}
\hline & 0 & M & D & E & $F$ & $M$ & A & Mr. & $J$ & $\sqrt{11}$ & $\mathrm{Ag}$ & $s$ & Total \\
\hline Tomporatures (.C) & 112 & 5.7 & 5.7 & 4.5 & 4.2 & 8.3 & 24 & 11.9 & 16.7 & 20.2 & 18.4 & 14,8 & \\
\hline Preclpltaclones $(\mathrm{cm})$ & 1.98 & 4.44 & 5.01 & 0.05 & 3.21 & 4.7 & 4.25 & 7.84 & 2.99 & 5.18 & 6.77 & 17.37 & 63.79 \\
\hline Indlce de calor & 3.39 & 1.22 & 1.22 & 0.85 & 0.77 & 2.15 & 2.6 & 3.72 & 6.21 & 8.28 & 7.19 & 5.17 & 42.77 \\
\hline Factor corrector & 0.96 & 0.83 & 0.81 & 0.84 & 0.83 & 1.03 & 1,11 & 1.24 & 1.25 & 1.27 & 1.18 & 1.04 & \\
\hline Evaporacion potencial & 4.68 & 1.85 & 1.8 & 1.41 & 1.29 & 3.55 & 4.41 & 6.49 & 9.7 & 12.29 & 10,25 & 7.02 & 64.74 \\
\hline Verlación de la reserva & 0 & 2.59 & 3.21 & -1.36 & 1.92 & 1.15 & -0.16 & 1.35 & -6.71 & -1.99 & e. & 10 & \\
\hline Reserva & 0 & 2.59 & 5.8 & 4.44 & 6.36 & 7.51 & 7.35 & 8.2 & 1.99 & 0 & e & 10 & \\
\hline Evaporaclón real & 1.98 & 1.85 & 1.8 & 1.41 & 1.29 & 3.55 & 4.41 & 6.49 & 27 & 7.17 & 6.77 & 7.02 & 53.44 \\
\hline Doflelt & 2.7 & & & & & & & & & 5.12 & 3.48 & & \\
\hline$x c$ & & & & & & & & & & & & 0.35 & \\
\hline
\end{tabular}


- un periodo seco muy corto (Julio y Agosto).

La tercera de las peculiaridades es el exceso de agua que se produce en Septiembre (Fig. 2).

Dos son los factores que nos han impulsado a estudiar lo ocurrido en este nuevo año hidrológico. Fundamentalmente, el hecho de que al final del año anterior, que acabamos de analizar, exite en el suelo la mayor concentración de agua posible, circunstancia que sólo se registra en este caso dentro de los 41 recogidos. Por otro lado, por segundo año consecutivo se mide un total de precipitaciones $\left(595^{\prime} 7 \mathrm{~mm}\right.$.) muy superior a la media de la serie considerada.

Así pues, arrancando de una reserva máxima de agua, y a pesar de que las lluvias son ligeramente inferiores a la evaporación potencial en Octubre, el suelo permanece de manera continuada saturado de agua desde Noviembre hasta Abril. En Mayo hay una variación negativa de la reserva que la reduce de manera sensible, si bien se recupera nuevamente en Junio. Aunque la evaporación potencial es muy alta en Julio, la reserva llega a cubrir la insuficiencia de las precipitaciones, e incluso queda un residuo que se consume en Agosto. Es este mes cuando se inicia la sequía que abarca también el de Septiembre.

Prácticamente la totalidad de lo sucedido en este año hidrológico resulta original y poco común. Por un lado, el suelo posee reserva de agua desde Octubre hasta Julio, e incluso queda saturado de agua entre Noviembre y Abril, existiendo un exceso que llega a alcanzar la cifra máxima de 4' $11 \mathrm{~cm}$. Por otra parte, el periodo seco no llega hasta Agosto, quedando reducido, como hemos dicho, a este mes y al siguiente (Fig. 2).

\section{CONCLUSION}

El objetivo del trabajo, en función del análisis parcial realizado, no es obtener unas conclusiones definitivas sobre las variaciones del balance hídrico teniendo presentes todos sus factores; ni tampoco establecer una tipificación de éstas atendiendo a sus causas o a su valoración cuantitativa. No obstante, si que podemos extraer unas primeras conclusiones, 
que en algunos casos no pasan de ser meras apreciaciones que deberán ser refrendadas por trabajos en los que se analice el hecho considerando un mayor número de variables.

Aplicando los índices de Thornthwaite encontramos algunas diferencias muy genéricas entre los distintos años analizados. Desde el punto de vista de la eficacia térmica, todos ellos pertenecen al grupo de los Mesotérmicos I, con evaporación potencial comprendida entre 57 y $71^{\prime} 2 \mathrm{~cm}$. Clasificados en función de la humedad predominan los años semiáridos, como resulta lógico dentro de un clima definido como tal; ahora bien, encontramos algunos años subhúmedos (1958-59 y 1987-88), secos subhúmedos (196869) y situados en el límite entre los ambientes semiárido y árido (1966-67). Según la variación estacional de la humedad la mayor parte de los años presentan un exceso de agua inexistente o pequeño, si bien a los años subhúmedos tan sólo les falta agua en verano.

Atendiendo a las diferentes fichas elaboradas, podemos señalar que sí existen algunas variaciones significativas en el desarrollo del balance hídrico de años hidrológicos con características pluviométricas distintas:

- La duración del periodo en el que el suelo posee reserva de agua, que habitualmente abarca desde Octubre o Noviembre hasta Mayo, se ve recortada en aquellos casos en los que las precipitaciones de otoño (ejemplo, 1954-55) o de invierno (1984-85) son excepcionalmente bajas. Por el contrario, se ve ampliada en años considerados húmedos en su conjunto (1958-59, 1959-60 y 1987-88), o en aquellos otros en los que durante el otoño se genera una reserva de agua muy cuantiosa que consigue ir cubriendo el deficit de lluvia durante un largo periodo (1965-66).

- El exceso de agua está muy lejos de producirse en el balance medio de los 41 años, donde el valor máximo de la reserva es de $3,36 \mathrm{~cm}$. Sin embargo, lo hemos detectado:

- durante años con un total anual de precipitaciones que podemos considerar normal, en función de unas precipitaciones muy cuantiosas de otoño (1965-66) o de otoño e invierno (1968-69). El periodo durante el que hay agua excedente no supera los 263 meses. 
Variaciones interanuales del balance hidrico en Teruel
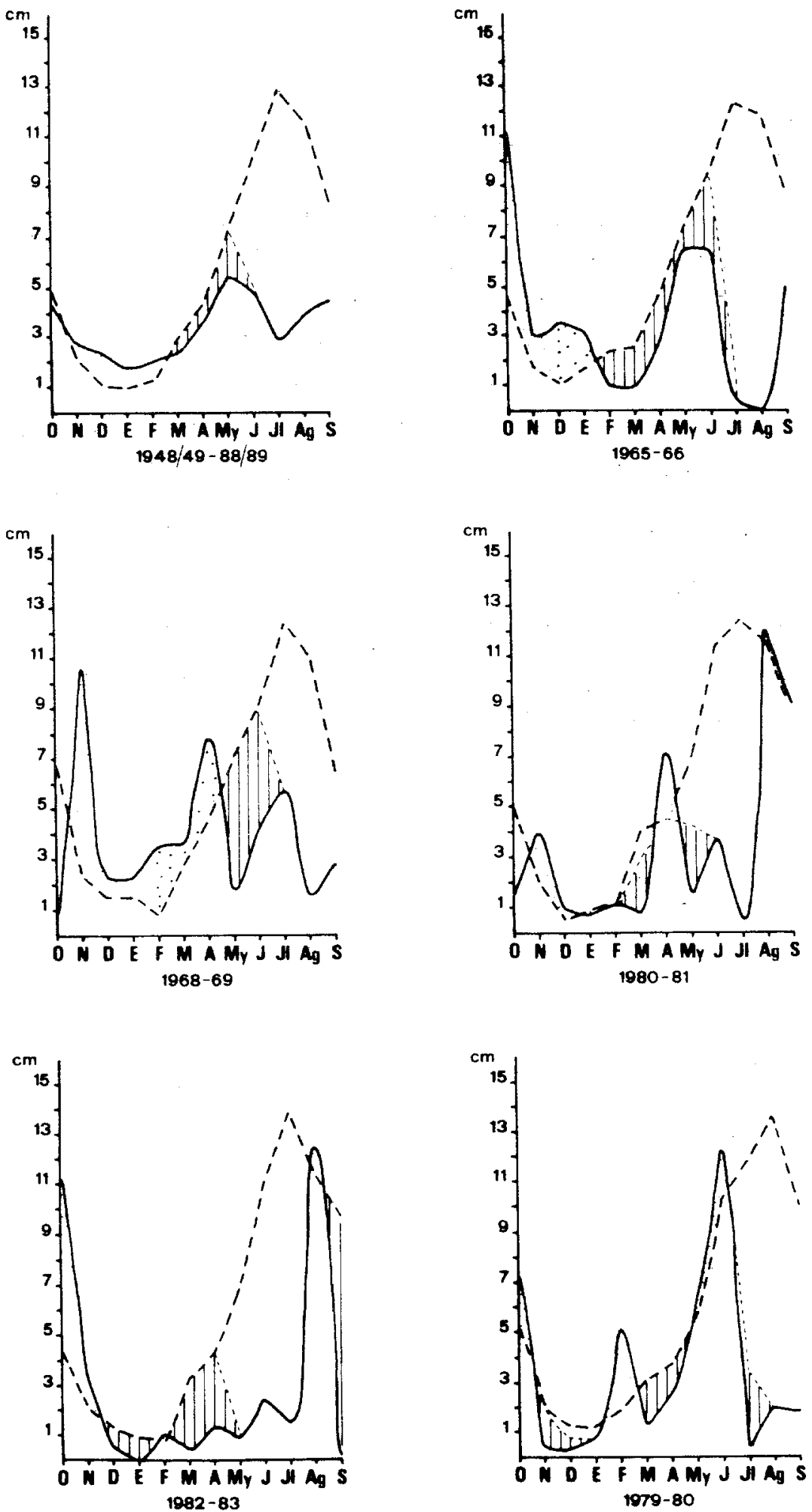

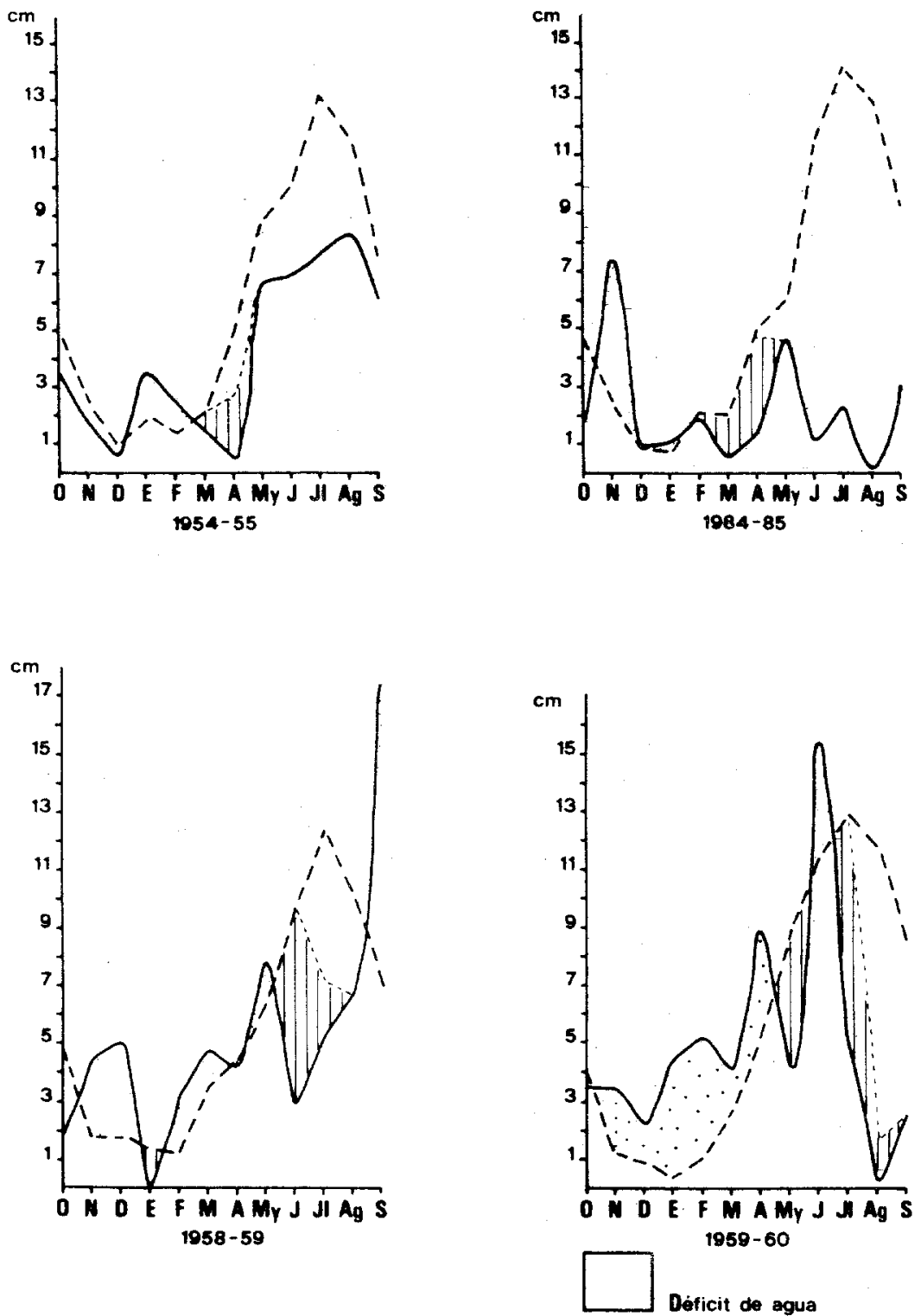

Déficit de agua

Precipitaciones

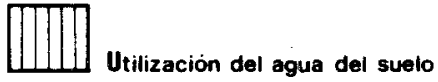

_. Evaporación potencial

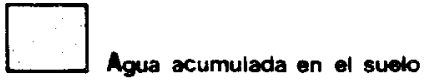

Evaporación real

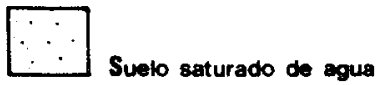

Fig. 2. Gráficas de evapotranspiración de algunos casos analizados 
- en años excepcionalmente húmedos, abarcando un periodo globalmente más largo que puede estar compartimentado en distintas fases (1987-88).

Comentario aparte merece el año 1959-60 en que hay exceso de agua desđe Noviembre hasta Abril, a causa de la acumulación de agua en el suelo producida en Septiembre del año hidrológico anterior y de las elevadas precipitaciones anuales. La primera de estas circunstancias, decisiva para la larga duración de la fase excedentaria, sólo se produce una vez en los 41 años contemplados.

No obstante, hay que hacer una observación. La ficha hídrica de 1958-59 nos permite apreciar que no todos los años que podemos considerar como muy húmedos en la zona van a presentar exceso de agua. Este puede no llegar a alcanzarse cuando la mayor parte de esas altas precipitaciones se concentran en verano, puesto que el resto del año no habrá suficientes precipitaciones para ello y en el estío la evaporación, dadas las elevadas temperaturas, será tan fuerte que resultará difícil la creación de reserva de agua en el suelo.

- El periodo seco aparece indefectiblemente en verano. Sólo muy excepcionalmente puede mostrarse desdibujado durante alguno de los meses estivales, debido al registro de precipitaciones de intensidad poco usual (1958-59, 1980-81, 1982-83).

Este periodo seco puede abarcar 2 meses de primavera o hasta la totalidad de esta estación. Sucede esto los años extraordinariamente secos (1966-67 y 1984-85), o aquellos otros en los que, aún con un total anual de precipitaciones normal e incluso ligeramente superior, las registradas durante algunas de las estaciones previas al verano son extremadamente bajas (1954-55, 1980-81, 1982-83). La propia primavera no tiene que marcar necesariamente una aridez extrema, aunque su porcentaje de lluvias si que está, al menos en los casos analizados, por debajo de la media. En alguno de estos años con sequía estacional muy marcada, pueden aparecer, asociadas a ella, otras fases con déficit de agua (Marzo de 1980-81, otoño de 1954-55).

- El comienzo de la variación negativa de la reserva, que conducirá al déficit estival, se produce generalmente en Marzo. Ahora bien, puede ocurrir que la escasez 
de precipitaciones de otoño e invierno (1980-81) lo adelanten dos o tres meses, o bien, en sentido inverso, que la abundancia de lluvias durantes estas estaciones lo demoren hasta más avanzada la primavera (Mayo de 1968-69).

- Finalmente, señalaremos que solamente durante algunos años muy secos y otros con bajas precipitaciones de otoño e invierno, desde Enero hasta Mayo se aprecian cambios continuos en el sentido de la variación de la reserva. Lo habitual es que en este periodo existan, exclusivamente, una primera fase de incremento de la reserva y otra a continuación de disminución.

\section{BIBLIOGRAFIA}

ASCASO, A. y CUADRAT, J.M. (1981): "El Clima". en HIGUERAS, A. (dir.): Geografía de Aragón, Tomo I, Guara Editorial. Zaragoza. pp.

CUADRAT,J.M. (1986): "La agroclimatología aragonesa: aspectos condicionantes del secano y del regadío". en El Sistema Agrario Aragonés (perspectivas y problemas) . Institución "Fernando El Católico" C.S.I.C. Zaragoza. pp. 11-33

FIDALGO, C. (1988): Metodología Fitoclimática. Colección Cuadernos de Apoyo, $\mathrm{n}^{\mathbb{Q}} 11$. Dpto. de Geografía. Ediciones de la Universidad Autónoma de Madrid. 122 p.

INSTITUTO NACIONAL DE METEOROLOGIA, Centro Zonal de Valencia. Fichas de resúmenes mensuales de Temperaturas y Precipitaciones.

JANSA, J.M. (1969): Curso de Climatología. Instituto Nacional de Meteorología. Ministerio de Transportes, Turismo y Comunicaciones. 445 p. Madrid.

PEÑA, J.L.; CUADRAT, J.M. y SANCHEZ, M. (en prensa): El clima de la provincia de Teruel. Cartillas Turolenses, $\mathrm{n}^{\mathfrak{2}}$ 17. Instituto de Estudios Turolenses. Teruel.

SANCHEZ-FABRE, M. (1985): "El clima de la ciudad de Teruel". Rev. Teruel, $\mathrm{n}^{2}$ 73, pp. 135-167. Instituto de Estudios Turolenses. Teruel

SANCHEZ-FABRE, M. (1989): Geomorfologia de la depresión de Alfambra-Teruel-Landete y sus rebordes montañosos. Tesis Doctoral. Dpto. de Geografia y Ordenación del Territorio. Universidad de Zaragoza. 926 p. y anexo cartográfico (inédita). 
Anexo I. Precipitaciones totales mensuales y anuales del periodo 1948/49. $1988 / 89$.

\begin{tabular}{|c|c|c|c|c|c|c|c|c|c|c|c|c|c|}
\hline & 0 & $N$ & D & $E$ & $F$ & $M$ & A & My & $J$ & J1 & Aa & $\mathbf{s}$ & Total \\
\hline 1948.49 & 3,25 & 0 & 41.2 & 5.7 & 19 & 4,5 & 16.7 & 68.1 & 47.7 & 8.9 & 22.5 & 63.7 & 330.5 \\
\hline 1949.50 & 8.7 & 13.3 & 22,2 & 5,9 & 0 & 16.3 & 21,8 & 103,3 & 0 & 8.4 & 72.9 & 1.1 & 273.9 \\
\hline 1950.51 & 31.1 & 6.5 & 75,4 & 28.8 & 14.9 & 32,3 & 55 & 28.8 & 39.3 & 14.8 & 61,2 & 119 & 507.1 \\
\hline 1951.52 & 59.1 & 20.2 & 34.7 & 31.4 & 9 & 23,9 & 47,6 & 24.2 & 90 & 68,5 & 116.8 & 5.9 & 531.3 \\
\hline 1952.53 & 18.6 & 18,4 & 23,6 & 18,2 & 9.5 & 0 & 26.2 & 2.3 & 57.9 & 13,5 & 30.3 & 28.4 & 246.9 \\
\hline 1953.54 & 30 & 7,2 & 47 & 12.4 & 39.7 & 80 & 24.4 & 55.7 & 66.2 & 12,9 & 0 & 2.5 & 378 \\
\hline $1954-55$ & 35.1 & 17 & 6,4 & 35,5 & 25,4 & 14,8 & 5,3 & 67 & 69.6 & 76.9 & 82.9 & 61,5 & 497,4 \\
\hline 1955.56 & 21,1 & 16 & 39.1 & 16 & 10.1 & 49,1 & 42.6 & 97,6 & 30,9 & 37.4 & 29.3 & 60,4 & 449,6 \\
\hline 1956.57 & 0 & - & 3.6 & 8 & 18.5 & 8.6 & 1.1 & 46,3 & 77.5 & 0 & 105 & 28,3 & \\
\hline 1957.58 & 161,7 & 37,2 & 6.4 & - & 7.2 & 33.7 & 13.4 & 27.9 & 37,8 & 8.5 & 27.8 & 38.9 & \\
\hline 1958.59 & 19.8 & 44,4 & 50.1 & 0.5 & 32.1 & 47 & 42.5 & 78.4 & 29.9 & 51.8 & 67.7 & 173.7 & 637.9 \\
\hline 1959.60 & 35.3 & 35.4 & 23.2 & 44,5 & 52.1 & 41.2 & 89 & 42.2 & 153,8 & 51.2 & 3 & 24.8 & 595.7 \\
\hline 1960.61 & 94.1 & 18 & 23,5 & 30.7 & 0 & 12.4 & 24.2 & 28.3 & 36 & 62.2 & 62.1 & 63.9 & 455,4 \\
\hline $1961-62$ & 54.9 & 52.6 & 28,3 & 33,5 & 12.2 & 26.5 & 42.2 & 121.5 & 42,5 & 13.5 & 12.3 & 125,8 & 565.8 \\
\hline $1962-63$ & 66,5 & 32 & 25,5 & 30.5 & 33 & 0 & 45 & 10 & 82.5 & 53 & 40.5 & 99.5 & 518 \\
\hline $1963-64$ & 5 & 34 & 49.5 & 0 & 30.5 & 8.5 & 16.5 & 82.5 & 109.5 & 20.5 & 17 & 32 & 405.5 \\
\hline 1964.65 & 22.5 & 10 & 53.5 & 18 & 20.5 & 28 & 6 & 38.5 & 22 & 10 & 33.5 & 25.5 & 288 \\
\hline 1965.66 & 111,5 & 30.5 & 35,5 & 32 & 10 & 9 & 26.5 & 65 & 64,5 & 3 & $Q$ & 50 & 437.5 \\
\hline 1966.67 & 51.5 & 16.5 & 0 & 13 & 12 & 22.5 & 41 & 2 & 3.5 & 26.5 & 4 & 9 & 2015 \\
\hline 1967.68 & 18.5 & 71.5 & 4. & 1.5 & 18. & 50 & 16 & 18 & 51.5 & 56 & 40 & 4 & 349 \\
\hline 1968.69 & 8.5 & 106 & 23,5 & 23 & 35.5 & 36 & 78 & 18.5 & 41.5 & 57.5 & 16.5 & 28 & 472.5 \\
\hline 1969.70 & 80 & 21,5 & 12 & 5.5 & 44,5 & 10.5 & 7 & 20 & 33 & 5.5 & 29 & 14.5 & 283 \\
\hline 1970.71 & 50 & 4.5 & 35 & 17 & 12 & 13.5 & 60 & 106.5 & 16 & 38 & 36 & 25.5 & 414 \\
\hline $1971-72$ & 23 & 25.5 & 49 & 20 & 8 & 30,5 & 11.5 & 85 & 19.5 & 152 & 31.5 & 103,5 & 559 \\
\hline 1972.73 & 35 & 33.5 & 3 & 8.5 & 5 & 7 & 22 & 15.5 & 101 & 8 & 40.5 & 18.5 & 297.5 \\
\hline $1973-74$ & 61.5 & 13 & 14 & 2.5 & 0 & 83 & 100 & 10.2 & 35,5 & 39. & 70.5 & 40 & 469.2 \\
\hline 1974.75 & 19.5 & 6 & 0 & 6.5 & 28 & 34 & 20.5 & 114,5 & 51 & 8 & 50.5 & 77 & 415.5 \\
\hline 1975.76 & 10 & 2.5 & 43 & 4 & 51 & 12.5 & 72 & 42.5 & 20.5 & 60 & 46 & 20 & 384 \\
\hline $1976-77$ & 46 & 5 & 37 & 42.5 & 7 & 16.5 & 42.5 & 72.5 & 39.5 & 24 & 39 & 50 & 421.5 \\
\hline 1977.78 & 38 & 215 & 34.5 & 22.5 & 23.5 & 3.5 & 35,5 & 83.5 & 26 & 0 & 19 & 17 & 324.5 \\
\hline 1978.79 & 12 & 8 & 22.5 & 43,5 & 20 & 19.5 & 40,5 & 32.5 & 80 & 28.5 & 2 & 51 & 360 \\
\hline $1979-80$ & 73 & 4 & 3 & 7.5 & 51 & 14.5 & 25.5 & 64.5 & 122 & 5 & 19.5 & 18.5 & 408 \\
\hline $1980-81$ & 15.5 & 39.5 & 10.5 & 7.5 & 11.5 & 8 & 71 & 16 & 37,5 & 5 & 120.5 & 91,5 & 434 \\
\hline $1981-82$ & 5 & $Q$ & 23 & 7 & 32 & 13.5 & 21.5 & 74.5 & 32 & 5.5 & 13.5 & 14 & 241.5 \\
\hline 1982.83 & 111.5 & 34 & 5 & 0 & 10 & 4 & 13 & 8.5 & 24 & 15 & 124 & 0.5 & 349.5 \\
\hline $1983-84$ & 10.5 & 61 & 22 & 7.5 & 7.5 & 24.5 & 28.5 & 104 & 20 & 2.5 & 32 & 10.5 & 330.5 \\
\hline $1984-85$ & 18.5 & 74 & 10.5 & 11 & 19 & 6 & 14.5 & 46. & 12 & 23.5 & 1.5 & 31. & 267.5 \\
\hline 1985.86 & 20.5 & 33 & 23,5 & 11.5 & 18.5 & 26 & 45 & 87.5 & 19 & 40 & $e$ & 99.5 & 424 \\
\hline $1986-87$ & 72.5 & 25 & 1 & 51.5 & 47 & 7.5 & 14 & 30 & 6.5 & 56.5 & 3 & 33 & 347.5 \\
\hline 1987.88 & 112 & 61 & 46.5 & 65,5 & 0.5 & 3.9 & 86.2 & 86.6 & 143,3 & 0 & 3.6 & 6.9 & 616 \\
\hline 1988.89 & 78.9 & 42 & 0 & 3.5 & 17.3 & 68.2 & 52.2 & 119.4 & 20.4 & 36.9 & 92.8 & 82.4 & 614 \\
\hline & & & & & & & & & & & & & \\
\hline MEDIA & 43.3 & 27.5 & 246 & 18.3 & 20 & 23.1 & 357 & 547 & 49 & 294 & 39.5 & 45.1 & 4102 \\
\hline
\end{tabular}


Anexo II. Temperaturas medias mensuales del periodo 1948/49 - 1988/89.

\begin{tabular}{|c|c|c|c|c|c|c|c|c|c|c|c|c|c|}
\hline & 0 & $\mathbf{N}$ & D & E & $F$ & $M$ & A & My & J & JI & $\mathrm{Ag}$ & $\mathbf{s}$ & Media \\
\hline $1948-49$ & 12.5 & 7.6 & 5 & 4.1 & 5.8 & 10,1 & 12.2 & 13.2 & 18,3 & 22.8 & 22.6 & 18.5 & \\
\hline $1949-50$ & 12.8 & 7.2 & 4.8 & 3.7 & 6.1 & 7.8 & 10 & 13.8 & 19.6 & 23.5 & 212 & 17.5 & \\
\hline $1950-51$ & 12.8 & 8.9 & 2.9 & 4 & 5 & 7.5 & 9.5 & 11.4 & 18.1 & 21,4 & 19.6 & 17.4 & \\
\hline 1951.52 & 9.9 & 7.3 & 5.2 & 0.8 & 3.6 &. & $\therefore$ & 14.5 & 19,5 & 21,2 & 20.2 & 16.1 & \\
\hline $1952-53$ & 13.7 & 7.9 & 4,3 & 1.7 & 3 & 6.2 & 10.9 & 16.5 & 17,2 & 22,4 & 22.4 & 17.8 & \\
\hline 1953.54 & 11.8 & 8.4 & 6.6 & 1.3 & 3.4 & 7.7 & 8.9 & 13.8 & 18.1 & 20.8 & 19.7 & 18,8 & \\
\hline $1954-55$ & 13,2 & 8.9 & 4.6 & 6.8 & 5,7 & 6,5 & 11.7 & 16.4 & 18.1 & 22 & 21,4 & 17 & \\
\hline 1955.56 & 12.5 & 6.5 & 6.2 & 5,1 & $-1,1$ & 7.5 & 10 & 13,3 & 17 & 19.9 & 20,4 & 17.8 & \\
\hline 1956.57 & 11,9 & 4.3 & 1,9 & 1.3 & 7,6 & 10.2 & 8.2 & 12.5 & 15.8 & 21.1 & 21 & 18 & \\
\hline $1957-58$ & 10.7 & 5.8 & 2 & 2.8 & 6 & 7.4 & 8.3 & 15,3 & 17.3 & 20.7 & - & 19.9 & \\
\hline 1958.59 & 11,2 & 5.7 & 5.7 & 4.5 & 4.2 & 8.3 & 9.4 & 11.9 & 16.7 & 20.2 & 18.4 & 14.8 & \\
\hline $1959-60$ & 10,4 & 5 & 4 & 1,9 & 4.3 & 7.4 & 11.6 & 16.2 & 19.5 & 21.3 & $21^{-}$ & 17.9 & \\
\hline $1960-61$ & 10.3 & 8.4 & 3.7 & 3.7 & 8.4 & 10.1 & 13.1 & 16.6 & 18.8 & 21,9 & 21.6 & 19.4 & \\
\hline $1961-62$ & 12.6 & 8 & 5.9 & 5.6 & 5.3 & 7.5 & 11.5 & 14.5 & 17.8 & 22.1 & 22.9 & 19.5 & \\
\hline 1962.63 & 14.9 & 5.6 & 3.2 & 5.5 & 3.1 & 8.7 & 11.2 & 14,5 & 18.5 & 21.7 & 20.2 & 16.4 & \\
\hline 1963.64 & 13.4 & 9.1 & 1.6 & 2.1 & 5.4 & 7.1 & 10 & 17.5 & 18.4 & 21.3 & 20.4 & 20.3 & \\
\hline $1964-65$ & 10.5 & 6.6 & 2.8 & 3,8 & 1.8 & 7.4 & 99 & 14.9 & 18.6 & 20.7 & 20 & 14.5 & \\
\hline $1965-66$ & 12 & 6.4 & 4.5 & 6 & 7.9 & 6.9 & 10,8 & 14,1 & 17.1 & 20.5 & 21.3 & 18.7 & \\
\hline $1966-67$ & 10.7 & 4.4 & 4.1 & 3,2 & 5.4 & 8.7 & 8.2 & 12.4 & 15,9 & 21,5 & 20,3 & 16.9 & \\
\hline 1967.68 & 14.5 & 72 & 1.9 & 3,7 & 5.4 & 6.7 & 10.2 & 12.5 & +6.9 & 21.1 & 19.3 & 17 & \\
\hline $1968-69$ & 15,3 & 7.6 & 5.1 & 4.9 & 3.1 & 7 & 9.9 & 13 & 15.8 & 20.2 & 19.7 & 14 & \\
\hline $1969-70$ & 12.1 & 6.2 & 3 & 5.5 & 4.6 & 5,3 & 9.6 & 13 & 17.7 & 20.5 & 19.8 & 19.1 & \\
\hline $1970-71$ & 10.9 & 8.9 & 0.8 & 2. & 4.8 & 4.2 & 9.5 & 11.5 & 15.7 & 19.6 & 19.9 & 17.4 & \\
\hline $1971-72$ & 13.2 & 4.8 & 4.5 & 2.2 & 4.9 & 7.4 & 9.2 & 123 & 16.5 & 19.8 & 18.7 & 14.1 & \\
\hline 1972.73 & 11.3 & 8 & 4.1 & 3,9 & 3.9 & 5.8 & 11.9 & 14,6 & 17.3 & 20.4 & 21.6 & 17.7 & \\
\hline $1973 \cdot 74$ & 11.9 & 7.9 & 3.2 & 5.5 & 4.8 & 6.8 & 8.6 & 14.9 & 17.6 & 20.6 & 20.5 & 16.8 & \\
\hline $1974-75$ & 8.6 & 7.5 & - & 5.6 & 5.7 & 6.1 & 9.6 & 11.3 & 16.9 & 22 & 20.6 & 16.1 & \\
\hline $1975-76$ & 12.7 & 2.1 & 3.5 & 3.5 & 5.2 & 7.1 & 8.5 & 14.7 & 18 & 20.2 & 202 & 16 & \\
\hline $1976-77$ & 10.4 & 5.6 & 6.5 & 4.3 & 6.8 & 8.6 & 11 & 11.8 & 15.9 & 18.8 & 18.4 & 18.4 & \\
\hline 1977.78 & 13.7 & 7,9 & 7 & 3.5 & 6.4 & 8.8 & 8.2 & 12.2 & 16.5 & 21,1 & 21.3 & 19.2 & \\
\hline $1978-79$ & 12.2 & 7.3 & 6.5 & 6.5 & 5.7 & 7.8 & 8.9 & 14.9 & 19.2 & 21.9 & 21.3 & 18.4 & \\
\hline $1979-80$ & 13 & 7.4 & 5.3 & 4.8 & 6.7 & 8.4 & 9.2 & 11.9 & 18 & 19.9 & 23,4 & 20.5 & \\
\hline $1980-81$ & 12,7 & 7.3 & 2.8 & 3.7 & 4.5 & 10.2 & 10.5 & 13.6 & 19.7 & 20.8 & 21.3 & 19.1 & \\
\hline 1981.82 & 13.9 & 9.6 & 6.5 & 6.1 & 5.2 & 7.9 & 10.7 & 14.8 & 20.6 & 23.1 & 21.5 & 17.9 & \\
\hline $1982-83$ & 11.6 & 7.9 & 5.5 & 4 & 4 & 2.1 & 10.4 & 13.5 & 19.2 & 22.8 & 20.6 & 20.2 & \\
\hline $1983-84$ & 14.3 & 10.6 & 5.4 & 4 & 4.5 & 5.3 & 12.2 & 9.7 & 17.9 & 23.3 & 20.6 & 17 & \\
\hline $1984-85$ & 12.5 & 92 & 4.3 & 4 & 8 & 6.8 & 11.7 & 12.5 & 19.9 & 23.1 & 22.9 & 19.7 & \\
\hline $1285-86$ & 15.2 & 72 & 5.2 & 4.7 & 4.6 & 8 & 8 & 17.1 & 18,9 & 22.2 & 21.6 & 18.5 & \\
\hline $1986-87$ & 13.5 & 76 & 4.5 & 3.1 & 5,2 & 92 & 122 & 13.9 & 19 & 21.1 & 22.7 & 20.1 & \\
\hline 1987.88 & 12.2 & 7.2 & 5.8 & 6.8 & $\because$ & 8.2 & 10.5 & 14 & 16.7 & 22.2 & 22.2 & 18.4 & \\
\hline 1988.89 & 13.1 & 8.1 & 4.1 & 4.7 & 7.5 & 11.1 & 9.9 & 16.3 & 19.8 & 24 & 24,1 & 18.1 & \\
\hline & & & & & & & & & & & & & \\
\hline MEDIA & 12.3 & 7.3 & 4.4 & 4 & 5 & 7. & 101 & 13.8 & 172 & 213 & 20.9 & 178 & 1 \\
\hline
\end{tabular}

